\title{
Excursions
}

Volume 5, Issue 1 (December 2014) Boundaries

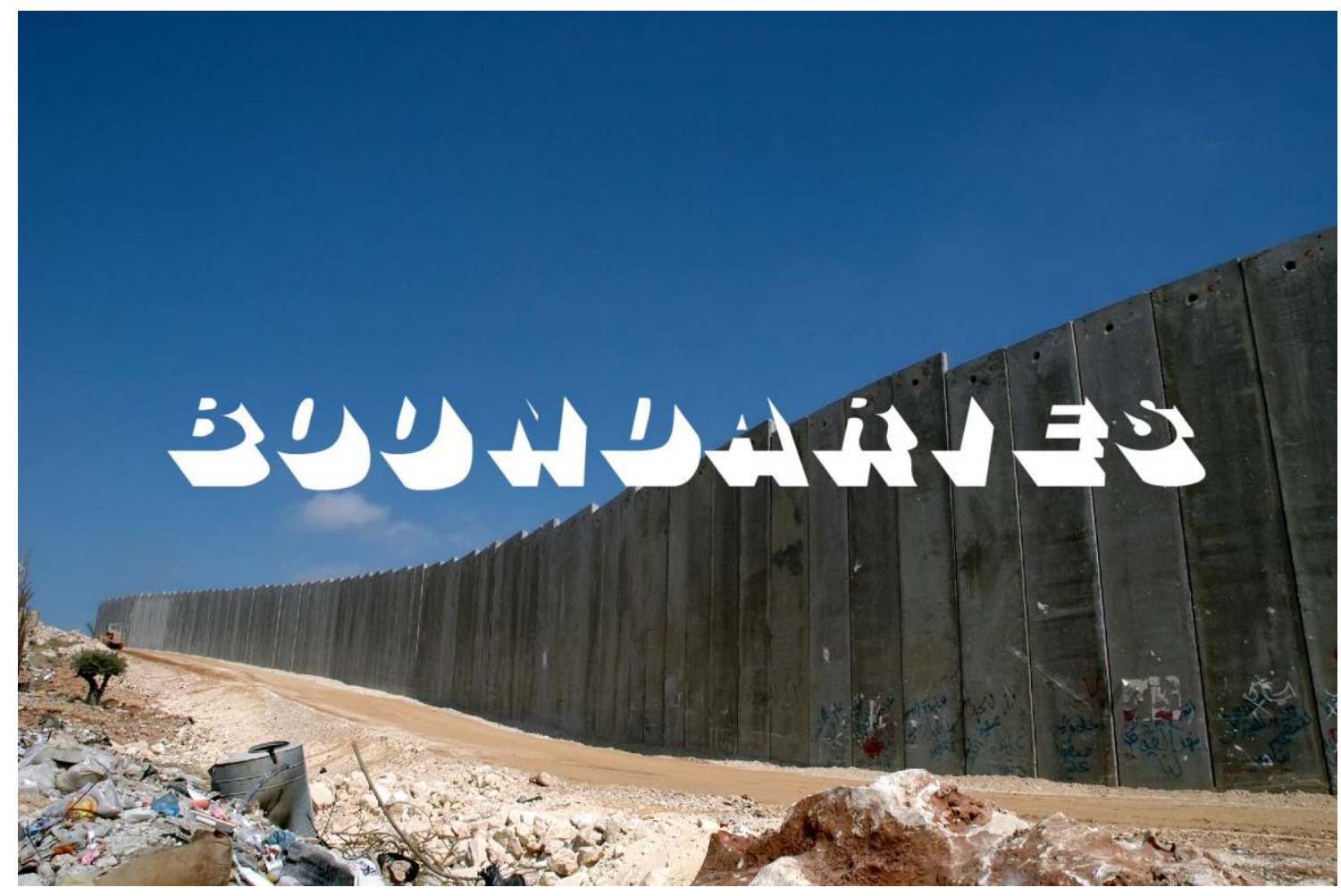

Cover photo: Justin Mclntosh

Cover design: Danny Bright

Michelle O'Brien, 'Alternative Narrative Forms, Exposure, and the Limits of Formalized Truth-Telling: Giving Accounts Though

New Methods in Indigenous Art'

Excursions, vol. 5, no. 1 (2014) 
Michelle O'Brien

University of British Columbia

\section{Alternative Narrative Forms, Exposure, and the Limits of Formalized Truth-Telling: Giving Accounts Though New Methods in Indigenous Art}

In First Person Plural, Sophie McCall (2011) discusses ongoing issues with truthtelling surrounding the historical - and ongoing - mistreatment of Indigenous peoples in Canada. While part of McCall's analysis focuses on Canada's now-defunct Royal Commission on Aboriginal Peoples (RCAP) in particular, it also touches upon the Indian Residential Truth and Reconciliation Commission (TRC), since the mandates of both organizations include uncovering the truth behind the atrocities committed during the residential school era. Specifically, the goals of both RCAP and the TRC suggest that, through the process of sharing grievances and uncovering the truth, "healing" and reconciliation might become possible (McCall, 2011, p.13). Yet McCall identifies the tendency for the Commission's reports to 'subsume testimonies within a dominant narrative of progress - from assimilation to self-government, from loss to recovery, from mutual mistrust to reconciliation' and that 'the need to

(C) Michelle O'Brien, 2014. License (open-access): This is an open-access article distributed under the terms of the Creative Commons Attribution License, which permits unrestricted use, distribution, and reproduction in any medium, provided the original work is properly cited. No warranty, express or implied, is given. Nor is any representation made that the contents will be complete or accurate or up to date. The publisher shall not be liable for any actions, claims, proceedings, demand or costs or damages whatsoever or howsoever caused arising directly or indirectly in connection with or arising out of the use of this material. 
preserve the report's narrative resulted in the paraphrasing, bracketing, or elimination of testimony' that did not fit with the commissions' 'stories of improvement' (p.113). McCall here identifies just some of the issues with the dissemination and sharing of individual truths in the context of governmentmandated organizations like RCAP and their reports, as these organizations often deprivilege the type of knowledge that is supposed to arise from process of truthtelling: that is, narratives that seek to find truth in personal experience without qualification. Indeed, critiques of the TRC, like McCall's, grapple with two fundamental concepts of truth, and I follow their use of the term. On the one hand, they evaluate the dominant narratives that have, over time, manifested as historical truth; on the other (and more significant for my study), they explore the mutable, often-ignored, and myriad truths found in personal accounts that are forgotten or occluded by these dominant historical truths. While reconciliation might require a process of 'truth-telling' that helps create space and 'legitimacy for accounts of individual experiences', current methods of collecting and sharing these personal truths clearly remain fraught and ignore much of the nuances and fissures in these personal histories (p.112).

However, RCAP's and the TRC's approaches are not the only ways that individual truths exploring the past, present, and future of Indigenous people can be imparted. As Emma LaRocque (2009) describes, new forms of oral storytelling, writing, performance art, and other artistic endeavours are complicit in bringing into public view the 'histories, invasions, and cultural values' of Indigenous people, while also indicating how their cultures remain 'live and dynamic' - and adaptable, I would argue (pp.162, 163). Artistic works - such as the performance art of AnishinaabeCanadian artist Rebecca Belmore, and the multimedia work of Kevin Lee Burton, who is Swampy-Cree - and their capability to impart narratives through diverse means therefore possess the potential to explore these issues through less constrained mediums. Yet official record produced by commissions, like RCAP, is thought to more accurately reflect the truth than the individual stories reflected through certain forms of Indigenous art because these artworks lack or preclude the same, easilycontainable narrative that these organizations prioritize.

I argue that by analyzing new forms of Indigenous art and aligning them with the Foucauldian notion of parrhesia - 'frank speech' or 'speaking truth to power" becomes apparent that these works locate individual truths that deal with the 
atrocities, ruptures, and even cultural continuity in Indigenous history that more official narratives might occlude. As such, I aim to identify a framework for engaging how these art forms create new venues for productive sites of truth-telling. I draw upon both Judith Butler's work on giving an account of oneself and Foucault's notion of parrhesia to provide a frame for this engagement; I also draw on these critiques to argue for innovations in Indigenous art as indicative of methods of giving personal accounts and truth-telling that exceed the containable narratives of formal documentation like RCAP's reports. While these interventions are rooted in Western critical theory, and are therefore limited in their approach, they are useful as they relate to and foreground the Anglo-European structures that govern these normative formulations of giving accounts and speaking truth, allowing for a sharper critique of these institutionalized demands for codified and easily-containable narratives of truth. I examine new interventions by Belmore and Burton, as their works are exemplary of how Indigenous artistic interventions continue to formulate new methods of speaking truth to power grounded in cultural-specific forms of narrating personal truths. By sharing accounts concerning communal traumas that have affected them, these artists grapple with exposing themselves through their art and the ensuing visibility of their personal stories, as well as the risk of being retraumatized by sharing these events. Further, by opening themselves up to personal exposure, these artists risk condemnation from their own communities and the general population due to their atypical approaches and the communal traumas they reference. However, I argue that in the creation of art that shares personal truths, while also acknowledging narrative absences and gaps, these artists convey Indigenous art's possibility to share truths that the official historical record might not otherwise acknowledge.

The notion of giving an account or relaying a personal testimony might seem straightforward, yet Butler indicates that the very formulation of these personal accounts always remains fraught and can never yield fully to conventional narrative forms. Specifically, Butler (2005) proposes that the 'I' can neither tell the story of its own emergence and origins, nor 'the conditions of its own possibility without bearing witness to a state of affairs [...] [that] are prior to one's own emergence as a subject who can know, and so constitute a set of origins that one can narrate only at the expense of authoritative knowledge' (p.37). Here, Butler identifies the impossibility of 
narrativizing a personal account that is not also enmeshed in external and unknowable discursive systems that precede the individual's account.

Butler locates further vexations in our dependence on norms and recognizable narrative structures to make our individual accounts intelligible to these interlocutors; in deploying these norms, however, we indicate that our singularity actually has features in common with our interlocutor(s) and others, and that aspects of our stories are therefore - to some degree - substitutable. Further, the 'you' who necessarily hears the 'I's' account is not only exterior to the individual's narrative, but also an 'internal condition' of this address, since our exposure to the other ${ }^{2}$ is what creates our singularity. In other words, our existence as an 'I' necessitates exposure to another, as this 'I' can only be distinguished when placed in relation to a 'you' (p.38). In effect, no account that we give of ourselves can be fully complete, as the individual account is constituted in part by its exposure to these external conditions. Further, Butler proposes that narrating our personal account is 'an act - situated within a larger practice of acts - that [...] constitutes a [...] social occasion for selftransformation' (p.130). In essence, giving an account of oneself is not only a method of constructing our sense of self, but also provides an opportunity to reframe our understanding of ourselves and the conditions that have affected us. We can therefore potentially subject these conditions to 'rupture or revision [...] or [to] contes[t] the hegemony' of normative forms of truth-telling (p.132).

As Butler engages with issues of telling the truth of oneself specifically, her argument dovetails with Foucault's (2010) discussion of parrhesia. Foucault initially identifies parrhesia as a way of truth-telling that exposes the speaker to risk by 'binding oneself' to the statement and act of telling the truth (p.65). Parrhesia does not produce a unified and discernable effect, but instead involves an unspecified risk (pp.62, 327). Specifically, the parrhesist fully believes that what they are saying is true, yet neither claims to know the truth nor attempts to persuade or convince the other; instead, the parrhesist frankly speaks the truth to another, and in doing so, risks censure, violence, and even death. While parrhesia and giving an account of oneself are not necessarily interconnected, Butler's discussion indicates that they can exist concurrently, and that the parrhesiatic account - not unlike sharing an account of oneself - can also cause the interlocutor to turn inwards. Put differently, parrhesia can incite others to self-reflect, and creates an imposition that can lead to interlocutors internalizing the struggle of speaker. Butler also states that Foucault's 
notion of parrhesia can concurrently include self-examination that takes place when one addresses the other (p.128). From this, I suggest that both truth-telling and giving an account of oneself can involve introspection for the 'I' giving the account, while also compelling their interlocutors to self-reflect. By giving an account of oneself - and in doing so, necessarily engaging with the structures that we are exposed to - individuals can also engage in a form of parrhesia as they share the truth of their experiences, yet also subject themselves to personal risk as a result.

The theoretical framework that I outlined - that of the problems and potential benefits of truth-telling and giving an account of oneself - have direct bearing on current issues with movements invested in pursuing reconciliation or reciprocity for Indigenous peoples in Canada. Indeed, giving a complete and true account of oneself is not only a codified part of RCAP's process, but, along with uncovering the truth, also remains a necessary barrier that an individual must pass through to receive official acknowledgment of their past grievances. In this sense, the work of RCAP does not align with parrhesia, as the parrhesiatic utterance emphasizes the freedom of the individual speaking and sharing their account, which, in the case of RCAP, is precluded by their carefully-managed and mediated work.

Indeed, RCAP and its offshoots, like the TRC, continue to struggle when attempting to mediate the traditional forms of testimonials from Indigenous peoples. As McCall (2011) notes, many Indigenous groups place a primacy on oral storytelling when sharing personal accounts, as well as on 'told-to' narratives, where interlocutors play a significant role in the construction of the account given by the individual; specifically, different audiences create different inflections, meanings, and nuances in the narrative' (p.40). Here, we can begin to see how current work in exploring the issues surrounding the dissemination of these accounts by Indigenous peoples share similar concerns with facets of giving an account of oneself and exposure that Butler identifies. For one to tell the truth of oneself, particularly in a culture where individual 'voice' is neither 'singular' nor 'pure', one must be exposed to an interlocutor who helps shape the account. Further, the account that one gives in these forms always supersedes the individual's personal narrative, and highlights the exposure of the individual to the histories that shaped their account.

Moreover, as LaRocque describes, there are frequently gaps and absences in the personal accounts of Indigenous individuals that, especially in formal, governmentmandated contexts like RCAP's hearings, call into question the 'authenticity' and 
completeness of these personal narratives. Bruce Granville Miller (2011) further states that a common argument made against oral histories or traditional means of disseminating communal stories in Indigenous cultures is that there is no meaningful way to show that these narratives are not "contaminated" and are based on culturally-coded transmission over generations, rather than on official or formal written records (p.85). In effect, the primacy RCAP places on the official rhetoric of individual 'testimonies', indicates a desire for quantifiable data and formal documents, while giving accounts of oneself in Indigenous culture is, as I suggested, often more fluid and nuanced. While these alternative means of sharing individual accounts still adhere to certain norms in order to make these narratives intelligible, the more unfettered and diverse forms of sharing an account in Indigenous culture means they are often less managed than the ones produced in formalized settings.

The constraints of RCAP's methodologies, as I outlined, clearly limit an individual's ability to give a personal account and speak the truth they wish to share. Yet as I suggested, RCAP's approaches are not the only ways that individual truths exploring the past, present, and future of Indigenous people in Canada can be imparted. Julia Emberley (2012) finds that while testimonial practices like 'documentary films, photography, and life-writings' are also part of institutional and representational 'regimes of violence', and thus risk 'recall[ing] dominant values of realism, truth, authenticity, and narrative cohesion', they do not necessarily reproduce those values: they can also inhabit the 'varied media of human regulation dialogically' and 'turn them to other purposes' (p.81). Yet I propose that for these practices to be viewed as equally productive forms of narrative and truth-telling, it is helpful to have a framework in place to understand the forms of truth that might appear in less familiar and non-institutionalized media, like performance or multimedia artworks.

Therefore, I will examine two recent works by Belmore (2002) and Burton (2012) as exemplary of the innovative potential for these alternate accounts to engage with tropes of exposure, truth-telling, and the process of giving an account of oneself. While both of these artists grapple with incomplete or eroded historical narratives, they nevertheless contribute to the reworking of the socially reified narrative surrounding Indigenous culture. As Dina Al-Kassim (2010) notes in her work on exposure, 'failures to narrate' and fragmented structures can actually be indicative of a radical form of parrhesia that can materialize the impasse or crisis of 
representation that is the political and public truth' (pp.161, 162). I will therefore explore both Belmore's performance art piece Vigil, which deals with the disappeared Indigenous women from Vancouver's Downtown Eastside (DTES), and Burton's interactive video project that explores the living conditions of the Indigenous peoples from the Canadian reserve God's Lake Narrows. I propose that their alternate approaches, which grapple with the way one is exposed to the other through art, can function as a productive form of parrhesia, providing new narratives that might otherwise remain untold through the limiting methods used by institutions like RCAP.

In Vigil, the notion of exposure to other individuals is immediately palpable, and is found in several levels throughout the piece. Before the public performance of Vigil commences, Belmore writes the names of missing Indigenous women from the DTES on her body. Belmore begins by reading the names of the women who were murdered by Robert Pickton, the man convicted of killing six women (most of whom were Indigenous) and she also shouts the names of other Indigenous women who have disappeared from the area. While Belmore's performance can be connected to the Pickton trial, it also gives voice to the larger issue of historical and ongoing violence against Indigenous women, and therefore connects to the issues that RCAP and the TRC's hearings attempt to contend with. However, Belmore's performance takes a markedly different tactic than the formality of the hearings when attempting to bring to public view these issues.

Next, Belmore (2002b) sanitizes the performance area by scrubbing the ground and the street, and lights candles to mark the site of her public vigil. After shouting each name, Belmore tears the head and leaves off a rose with her mouth to indicate the loss of the future of these women and the general indifference toward their disappearance. Belmore then dons a red dress, nails the skirt to a pole or a fence, and thrusts herself forward while grabbing at the dress until it is torn in shreds from her body and she stands exposed in her underclothes. This is Belmore's (2002a) attempt to represent the 'tattered lives of women forced onto the streets for their survival in an alien urban environment' (para. 1). Belmore's website also states that through this act, she 'lets each woman know that she is not forgotten: her spirit is evoked and she is given life by the power of naming' (para. 1). In short, Vigil aims to memorialize the lives of Indigenous (and some of the non-Indigenous) women in the DTES, while also rupturing the silence surrounding their deaths and disappearances. 
Through Vigil, Belmore not only makes these women's stories visible, but she also exposes herself, and addresses the audience who views her performance. When Belmore places the candles around the site of her performance, she also takes some of the viewers by the arms and invites them to light some of the candles. Belmore first asks a young white man to light a votive, and as Emberley (2012) states, this 'act of hospitality immediately crosses the identity-difference line' and makes this 'young white male an unwitting member of her performance' (p.81). I argue, though, that this invitation on Belmore's part - and indirectly asking him to acknowledge her narrative - also constitutes herself in a particular way; specifically, it can be seen as creating a particular form of exposure that supersedes her account and the specific interactions between a white male (Pickton) and Indigenous women that comprise the initial framing of her piece, and instead references severe traumatic historical incidents. While Emberley primarily reads Belmore's act as an instance of hospitality that establishes a more equitable relationship between the two, Belmore's exposure also brings forth the pre-existing legacy of violence between white males and Indigenous women in Canada. Indeed, Vigil took place during the Pickton trial, when the large-scale neglect of missing and murdered Indigenous women in general momentarily received long-awaited critical and media attention. Belmore places herself in the position of the women exposed to this brutality and inadvertently suggests that she herself could conceivably be in the place of one of the missing women. However, she does not directly narrate what this exposure signifies to the young man and the predominately white audience. Belmore's narrative is therefore imbued with the untellable and the unintelligible that cannot be expressed through documented testimonies or other formulaic methods of sharing an individual's story.

As Belmore's dress is wrenched from her body, her body becomes a literal site of exposure. Through the aforementioned act of speaking their names and inscribing them on her body, Belmore also exposes the identities of the women and memorializes them through her art. Yet save for when Belmore yells the women's names, much of the performance is done in silence, and is fragmented as Belmore paces around and takes her time before reading the names scrawled on her arms. Through this, Belmore again keeps intact the unknown about these women; this act is markedly distinct from official record, which attempts to explain the gaps in accounts concerning Indigenous women when their disappearances or deaths enter into public view. For some women, their families had not seen them in almost a decade before 
their disappearance, and their lives after they left home remain ambiguous or altogether unknown (Emberely, 2012, p.71). Here, Vigil also reflects a site of parrhesia: Belmore is exposed and made vulnerable, and through her performance and enacting what she believes to be the truth surrounding the women's disappearances, creates what Foucault (2010) describes as 'a fracture and opens up the risk: a possibility, a field of dangers, or at any rate, an undefined eventuality' as her performance does not strive for narrative closure (p.62). Given that the truth of these women's lives necessarily includes these gaps that cannot be supplemented and rendered through traditional testimonial or narrative forms, Vigil can be read as a parrhesiatic enunciation that also differs from Foucault's emphasis on speech, as it includes instances of silence, interactivity, and movement that visually and aurally depict the truth of these women's lives.

Unlike Belmore's account, Burton's (2012) project on God's Lake Narrows, the reservation in northern Manitoba that Burton is from, is more directly an individual giving a narrative account of his self, while also referencing larger social issues that affect the community and Indigenous people across Canada. Burton's multimedia project is currently available on the National Film Board's website, and allows viewers to interact with slides of images and text that serve as Burton's account of how he views God's Lake Narrows. The description accompanying the video informs us that Burton intends to reposition the narratives surrounding 'poverty, illness, abuse and death' that surround Indigenous life on the news, but Burton also identifies himself as one of the 'I's telling the story about God's Lake Narrows by placing himself in the opening scene. Burton's ultimate goal is to show the truth of 'reserve life' as he knows it and force viewers to engage and interact with the images of the reserve by clicking on the different slides; reading the texts; listening to the stories, voices, and music that plays in the background (most of which does not align with the image on the screen); and navigating through the website. As Burton's curatorial statement suggests, the view of 'reserve life' presented is 'anything but voyeuristic: Burton's subjects stare out at us, storied, self-made, engaged' (Burton para. 3). At the same time, by placing himself within the project and sharing his own story about how he struggled as a young gay male in God's Lake Narrows, Burton makes himself visible and exposed together with the subjects he includes in his project, and thus gives an account of himself alongside the other residents of God's Lake Narrows who appear in his multimedia artwork. 
Although the residential school system is not mentioned until halfway through the images and text slides, Burton, unlike Belmore, makes a direct connection between the current conditions of God's Lake Narrows and its inhabitants and 'segregation, reserve placement, and residential schools': all issues that RCAP has documented in great detail over the course of its tenure. Like Belmore's work, Burton's intervention is an alternative form of exposure to those found in works created through more institutionalized settings. Butler writes that when encountering another individual, 'the uniqueness of the other is exposed to me, but mine is also exposed to her' (p.34). In the images and stories shared through Burton's piece, this exposure initially seems one-sided: the people who share their accounts are exposed through Burton's piece, but their other interlocutors (those viewing the work online) are not made visible to them. Yet as the statement on Burton's website indicates, his work aims to expose us to those we are viewing by forcing us to look directly at them, as we try to make sense of the narrative pieces we are given, and physically interact with the multimedia work.

The initial images of Burton's project are houses in God's Lake overlaid with text that gradually fades in and out, informing the viewers that while the houses may look the same to the uninitiated, the reserve inhabitants can possibly determine information about the people who own the houses from their exteriors. Burton thus immediately foregrounds that standard narrative interpretive tools are inadequate when dealing with the complexity of reserves like God's Lake. A standard account of an individual might not include information about a person's 'porch door' or 'fourwheeler', but for Burton these images play a role in telling the truth of an individual's story, such as their economic conditions, their hobbies, their family size, and how they differentiate themselves from their neighbours. The images of houses then shift to slides featuring people in their homes staring directly at the viewer, with their individual narrations playing in the background. The individuals in the background of the images are generally engaged in the quotidian: a smiling woman in a living room holds a baby up into view, while in the background a teenage girl sits at a computer and a teenage boy plays the guitar. In another, a man in a substantially more ornate home stares at the viewer with his arms crossed, while two young boys sit with their laptops and a young woman holds a baby. The narrations in the background are completely without context: a man reads bingo numbers, a woman recites what sounds like a list of community events, and another woman softly lists names. Burton 
thus provides a venue for a different account of the individuals who live in God's Lake Narrow to be told, yet similar to Belmore's work, does not attempt to turn these stories into coherent narratives. As Butler states, the accounts that we give 'are taken away as [we] give them, interrupted by the time of a discourse that is not the same as the time of [our] life [...] since the indifferent structures that enable [our] living beyond to a sociality that exceeds [us]' (p.36). Similarly, the 'stories' presented of individuals from God's Lake Narrows - and even Burton's own narrative about growing up there as a gay youth - clearly exceed the time and space that these accounts are initially given in, and are only fully constituted when there is an interlocutor to engage with them.

In this sense, the site of exposure that Burton creates by making visible the stories of the residents is markedly different to the methods of collecting and disseminating accounts that the official testimonies make use of, even though they both touch upon similar issues (such as the widespread poverty and the cultural disconnects created through both the reserve and residential school systems). While Burton's work on God's Lake Narrows risks exposing both himself and the inhabitants to historical traumas by partially framing his work in relation to structures like the residential school system, it also formulates their accounts in a new way, one that can contest the more strictly delineated accounts of cultural discontinuity that are produced in official arenas.

Butler also states that to be exposed to or placed in relation to another is a 'primary necessity, an anguish', but she points out that it is equally 'a chance - to be addressed, claimed, bound to what is not me, but also to be moved, to be prompted to act, to address myself elsewhere' (p.136). Burton's work on God's Lake Narrows seems indicative of these two tensions, as he speaks frankly through his textual narration and images about the problematic condition of the community; however, he also places the inhabitants in relation to a different set of interlocutors - those who interact with the website - and subsequently indicates that their stories can be told in vastly different ways. In this way, Burton's work, I propose, is also engaging in a form of parrhesia not unlike Belmore's. Foucault (2010) states that 'discourses of truth' deserve more than to be analyzed according to the 'measure and from the point of view of a history of ideologies which would ask them why they speak falsely, failing to telling the truth' (p.309). In short, we should not measure the facticity or authenticity against dominant forms of truth-telling that would find Burton's work to fail to tell 
the "whole" truth, given the lack of cohesive narration and the numerous aspects of the individual stories that are left unknown. Instead, the formation of his multimedia project is itself engaging with the truth - the truth as Burton understands it - of God's Lake Narrows: it is rife with unrecoverable stories as we remain barred from much of the narration and it is a struggle to make sense of the layers of fractured narratives at play (the audio recordings, the text, the photographs, the music). However, it also shows individuals giving accounts of themselves as community members whose stories extend far beyond the scope of narratives surrounding the issues with reserves. Like Belmore, Burton therefore presents a form of parrhesia that does not rely on speech alone, but on fragmentation, interactivity, and the visual alongside the oral/aural to express truth through means that align more with the diversity of how accounts are given in Indigenous cultures. Indeed, Burton's work makes sense of the exposure of Indigenous people in a radically different way from official record, in part by drawing us in as interlocutors to partake and participate in making visible their fragmented stories.

While RCAP and the TRC both mediate personal accounts and formalize and legislate what constitutes truth-telling, I have attempted to convey that these new interventions in Indigenous art present some of the ways that alternate methods of truth-telling can occur. Through the framework created by synthesizing the work of Butler and Foucault, it is possible to see that while Belmore's and Burton's work may contain narrative gaps and make use of atypical means of sharing accounts, they nevertheless engage with a form of parrhesiatic utterances. As Foucault (1988) notes, change does not 'take the form of a sudden illumination in which "one's eyes are opened"' (p.264). Indeed, for change to occur through a repeated and conscientious engagement with the truth, we must therefore make use of these different theoretical frameworks to make alternate forms of truth-telling intelligible in the face of prevalent and mediated narratives of truth that are disseminated through organizations like RCAP and the TRC. At the same time, these artists reframe and move beyond the limits of the Foulcauldian concept of parrhesia, indicating that parrhesiatic utterances for Indigenous individuals can also take the form of engagements with narrative gaps and the sharing of concurrent accounts through more complex means like interactive accounts and the visual, as well as the oral. Specifically, these methods can help rework our perceptions and expectations through our affective responses and participation in these narratives. The work of 
these artists do not have immediate impact on how the truth about Indigenous experiences are rendered as legislature in Canada; however, they do the important work of complicating circumscribed narratives that render the "truth" of Indigenous histories and the process of giving an account of oneself into easily-containable narrative segments. Although the accounts that artists like Belmore and Burton give might be focused on particular places and times, through the exposure seen in their work they reference diverse histories, and provide a rich foundation for considering the myriad truths of Indigenous experience in new ways. 
Excursions 5:1

\section{Notes}

1 Foucault uses the term 'speaking truth to power' to refer to instances of speaking fearlessly, particularly when the speaker is in a position of inferiority in relation to the interlocutor.

2 In the context of Butler's theory that I draw throughout this paper, the 'other' does not to refer to a particular marginalized person, but simply to another person (in this case, an interlocutor). 


\section{Bibliography}

Al-Kassim, D., 2010. Exposure, Biopolitics and Radical Parrhesia in Postapartheid Literature and Culture. Localities. 4, pp.149-172.

Archibald, J. 2008. Indigenous Storywork: Educating the Heart, Mind, Body, and Spirit. Vancouver: UBC Press.

Belmore, R., 2002a. Vigil. Talking Stick Festival, Full Circle, First National Performances Firehall Theatre, Vancouver, BC. Available at:

http://rebeccabelmore.com/video/Vigil.html [Accessed on 7 March 2014]. 2002b. Vigil. [video file] Available at:

http://rebeccabelmore.com/video/Vigil.html [Accessed on 7 March 2014].

God's Lake Narrows, 2011. [Film] Directed by K.L. Burton and A. Smith. Canada:

National Film Board of Canada. Available at: http://godslake.nfb.ca/\#/godslake [Accessed on 7 March 2014].

Butler, J., 2005. Giving an Account of Oneself. New York: Fordham University Press.

Report of the Royal Commission on Aboriginal Peoples, 1991. Available at:

http://www.ainc-inac.gc.ca/ch/rcap/sg/sgmm_e.html [Accessed on 7 March 2014].

Castellano, M.B., 2008. A Holistic Approach to Reconciliation: Insights from Research of the Aboriginal Healing Foundation. From Truth To Reconciliation: Transforming the Legacy of Residential Schools. Ottawa: Aboriginal Healing Foundation, pp.383-402.

Cruikshank, J., 1998. The Social Life of Stories: Narrative and Knowledge in the Yukon Territory. Lincoln: U of Nebraska P.

Emberley, J., 2012. Breaking the Framework of Representational Violence: Testimonial Publics, Memorial Arts, and a Critique of Postcolonial Violence. C. Kim, S. 
McCall, and M. B. Singer, eds. Cultural Grammars of Nation, Diaspora, and Indigeneity in Canada. Waterloo: Wilfred Laurier Press, pp.65-82.

Foucault, M., 1988. The Concern for Truth. L. D. Kritzman, ed. Politics Philosophy Culture. Routledge: New York. 2001. Fearless Speech. J. Pearson, ed. Los Angeles: Semiotext(e). 2010. The Government of Self and Others: Lectures at the Collège de France 1982-1983. Trans. G. Burchell. New York: Palgrave MacMillan.

Hoy, H., 2001. 'How Should I Eat These?' Eden Robinson's Traplines. H. Hoy, ed. How Should I Read These?: Native Women Writers in Canada. Toronto, Ont: University of Toronto Press, pp.153-182.

Jacobs, B. and Williams, A.J., 2008. Legacy of Residential Schools: Missing and Murdered Aboriginal Women.

From Truth to Reconciliation: Transforming the Legacy of Residential Schools. Ottawa: Aboriginal Healing Foundation, pp. 119-43.

LaRocque, E., 2009. Reflections on Cultural Continuity through Aboriginal Women's Writings. Guimond, E., Stout, M., and Valaskakis, G., eds. Restoring the Balance: First Nations Women, Community and Culture. Winnipeg: University of Manitoba Press, pp.149-74.

McCall, S., 2011. First Person Plural: Aboriginal Storytelling and the Ethics of Collaborative Authorship. Vancouver: U of British Columbia P.

Miller, B.G., 2011. Oral History on Trial: Recognizing Aboriginal Narratives in the Courts. Vancouver: U of British Columbia P.

Smith, D. A., 2009. Research Notes: The Royal Commission on Aboriginal Peoples Transcripts Online. Natives Studies Review 18 (2), pp.135-139.

Truth and Reconciliation Commission of Canada, 2012. Available at: http://www.trc.ca/websites/trcinstitution/index.php?p=10 [Accessed on 7 March 2014].

Wolski, E., 2010. The Role of Culturally Relevant Gender-based Analysis in Reconciliation. Response, Responsibility, and Renewal. Ottawa: Aboriginal Healing Foundation, pp. 269-83. 